\title{
La muerte al instante: telegramas y notas de pésame en la Argentina peronista
}

Resumen: El artículo analiza telegramas y notas de pésame enviados al presidente argentino Juan Perón con motivo de la muerte de su esposa, Eva Duarte, en julio de 1952. Se argumenta que estos textos breves expresaron normas sociales, reglas sobre cómo y qué sentir y que también intentaron en ocasiones comunicar experiencias emocionales relacionadas con la muerte y las relaciones de poder. El fallecimiento de la mujer más poderosa de la Argentina lubricó una comunidad política peronista que era también una comunidad emocional. El artículo dialoga con la bibliografía sobre la muerte escrita, sobre la historia de las emociones y sobre la historia del peronismo.

Palabras clave: muerte escrita, normas, experiencias, comunidad emocional.

\section{Right on time death: telegrams and condolence letters in Peronist Argentina}

Abstract: This paper analyzes telegrams and condolence letters sent to Argentine President Juan Perón on his wife Eva Duarte's death in July 1952. It suggests that these brief texts convey social norms, rules on how and what to feel, and seek to communicate emotional experiences related to death and power relations. The death of the most powerful woman in Argentina strengthened a Peronist political community that was also an emotional community. The paper dialogues with the bibliography on written death, the history of emotions, and the history of Peronism.

Keywords: written death, norms, experiences, emotional community.

\section{Na hora da morte: telegramas e notas de condolências na Argentina peronista}

Resumo: 0 artigo analisa telegramas e notas de condolências enviadas ao presidente argentino Juan Perón pela morte de sua esposa, Eva Duarte, em julho de 1952. Argumenta-se que estes textos breves expressaram normas sociais, regras sobre como e o que sentir e, também, que tentaram comunicar experiências emocionais relacionadas com a morte e as relações de poder. 0 falecimento da mulher mais poderosa da Argentina fortaleceu uma comunidade política peronista que era também uma comunidade emocional. 0 artigo dialoga com a bibliografia sobre a morte escrita, sobre a história das emoções e sobre a história do peronismo.

Palavras-chave: morte escrita, normas, experiências, comunidade emocional.

Cómo citar este artículo: Sandra Gayol, “La muerte al instante: telegramas y notas de pésame en la Argentina peronista”, Trashumante. Revista Americana de Historia Socia/ 18 [2021]: 168-189.

DOI: 10.17533/udea.trahs.n18a08

Fecha de recepción: 16 de septiembre de 2020

Fecha de aprobación: 13 de noviembre de 2020

Sandra Gayol: Doctora en Historia por la École des Hautes Études en Sciences Sociales. Profesora Titular en la Universidad Nacional de General Sarmiento e Investigadora Principal del Consejo Nacional de Investigaciones Científicas y Técnicas [Conicet]. ORCID: 0000-0003-3624-2119. Correo electrónico: sandra.gayol@gmail.com 


\title{
La muerte al instante: telegramas y notas de pésame en la Argentina peronista*
}

\author{
Sandra Gayol
}

\section{Introducción}

$E^{1}$ 4 de agosto de 1952, Antonio Ber Ciani envió un telegrama a la Subsecretaría Antonio pide al presidente "acepte mis sinceros testimonios de dolor por la fatalidad que enluta hoy el corazón nacional”. ${ }^{1}$

Esa noche, la hora de origen del mensaje fue a las 21:15 y la de recepción a las 22:45, Eva Perón seguía siendo velada en el Ministerio de Trabajo y Previsión de la ciudad de Buenos Aires. En los 15 días que duró su funeral, miles de personas se movilizaron para participar en sus exequias. No solo fue el velatorio más largo de la historia argentina, y posiblemente el más multitudinario, sino que se convirtió en el evento más importante de ese año y devino en una bisagra para el gobierno peronista.

Es muy probable que Antonio, quien vivía en la ciudad de Buenos Aires, haya ido por lo menos una vez al velorio. También es probable que se haya involucrado activamente en la miríada de homenajes oficiales y en los que por iniciativa popular inundaron la república. Su nota de pésame fue otra forma de participación fúnebre que tenía una historia tras de sí. En pequeñas esquelas, por medio de cuidadas tarjetas o de cartas, los seres humanos se manifestaban ante la pérdida. Con la expansión del alfabetismo y el desarrollo de una infraestructura de comunicaciones

* Este artículo es parte de un proyecto de investigación financiado por el Consejo Nacional de Investigaciones Científicas y Técnicas (CONICET), y la Universidad Nacional de General Sarmiento (UNGS). Agradezco a María Bjerg, Silvina Merenson y Sara Perrig sus comentarios a una versión preliminar de este artículo. Gracias también a los pares evaluadores de Trashumante. Revista Americana de Historia Social.

1. Antonio Ber Ciani, Capital Federal, 4 de agosto de 1952. Archivo General de la Nación Argentina (AGNA), Buenos Aires, Archivo Intermedio, Secretaría Legal y Técnica de la Presidencia de la Nación, Fondo Fiscalía Nacional de Recuperación Patrimonial, Comisión 21, caja 4. Todos los documentos citados en este artículo corresponden a este fondo y a esta comisión. Agradezco a Silvana Ferreyra sus sugerencias de búsqueda en los meandros del fondo. Salvo excepciones, que aparecen explicitadas, el destinatario fue el presidente de la nación. 
—desde el tendido de cables hasta la construcción de edificios-, el mensaje de Antonio fue posible. ${ }^{2}$ Muchísimo más veloz que una carta, el telegrama, además de usarse para los negocios y las relaciones diplomáticas, se reservaba para los grandes acontecimientos, como los nacimientos, los casamientos y la muerte. En una frase breve, el remitente expresaba su involucramiento personal con el evento o con la persona a quien estaba dirigido. Es lo que hizo Antonio por la muerte de Eva.

$\mathrm{Su}$ "testimonio de dolor" se insertaba en un espacio epistolar que la política también había contribuido a edificar. En las décadas centrales del siglo XX, la escritura de cartas públicas fue estimulada globalmente por los políticos como un modo de acortar distancias con la población. ${ }^{3}$ El presidente norteamericano Roosevelt, el brasileño Vargas y varios mandatarios mexicanos, por ejemplo, propiciaron "una política de masas de la escritura política". ${ }^{4}$ Con motivo del lanzamiento del segundo plan quinquenal en 1951, como han demostrado varios estudios, el presidente de la Argentina Juan Domingo Perón invitó a la población a mandarle recomendaciones. ${ }^{5}$ Se sabe de la importancia y la cantidad de peticiones que hombres y mujeres realizaron por medio de cartas a Perón y a Eva. Antonio probablemente ya había escrito a los líderes, a otros funcionarios del gobierno o a alguna agencia estatal. Su telegrama de pésame, que nadie le pidió, se inscribía entonces en una práctica mortuoria y política que ayuda a comprender, además, cientos de actitudes similares a la suya.

2. Adriana Collado, "Arquitectura moderna para el servicio postal - Argentina, 1947-1955", Arquitectura moderna y Estado en Argentina: edificios para correos y telecomunicaciones (1947-1955), ed. Adriana Collado (Buenos Aires: Centro de Documentación de Arte y Arquitectura Latinoamericana / Facultad de Arquitectura, Diseño y Urbanismo de la Universidad Nacional del Litoral, 2013) 29-54.

3. María José Ortiz Bergia, "Cartas públicas: claves metodológicas y usos históricos posibles", Prohistoria 22.31 (2019): 161-180.

4. Leila Sussman, citado en Ortiz Bergia 167.

5. Donna J. Guy, Creating Charismatic Bonds in Argentina: Letters to Juan and Eva Perón (Albuquerque: University of New Mexico Press, 2016); Eduardo Elena, "What the People Want: State Planning and Political Participation in Peronist Argentina, 1946-1955", Journal of Latin American Studies 37.1 (2005): 81-108; Omar Acha, "Sociedad civil y sociedad política durante el primer peronismo", Desarrollo Económico 44.174 (2004): 199-230; Omar Acha, "Cartas de amor en la Argentina peronista: construcciones epistolares del sí mismo, del sentimiento y del lazo político populista", Nuevo Mundo Mundos Nuevos (2007): 1-14, doi: 10.4000/nuevomundo.12272; Hernán Comastri, "Territorio, Estado e imaginación técnica popular durante el primer peronismo: políticas públicas, prensa y cartas a Perón (1946-1955)", Estudios Sociales del Estado 4.8 (2018): 124-150, doi: 10.35305/ese.v4i8.130; Hernán Comastri, "Productividad y política obrera desde las bases: la imaginación técnica popular en las cartas a Perón (1946-1955)", Quinto Sol 24.1 (2020): 1-18, doi: 10.19137/qs.v24i1.3571; Rosa Aboy, "El 'derecho a la vivienda'. Opiniones y demandas sociales en el primer peronismo”, Desarrollo Económico 44.174 (2004): 289-306, doi: 10.2307/3456039; Florencia Gutiérrez, "Vivir en un pueblo azucarero: entre el asistencialismo empresarial y el derecho al bienestar. Tucumán durante el primer peronismo", Comunidades, historia local e historia de pueblos. Huellas de su formación, ed. Mirta Zaida Lobato (Buenos Aires: Prometeo Libros, 2020) 75-98. 
En el Archivo General de la Nación (AGNA) de la República Argentina pude consultar 388 telegramas y 180 tarjetas de pésame que hombres, mujeres y organizaciones enviaron al presidente por la muerte de su esposa. Quizás por su economía de palabras y su tendencia prescriptiva y a la repetición, estos documentos no han interesado a los investigadores. Sin embargo, entre el encabezado y la despedida final, todos casi idénticos, se perciben matices que brindan la oportunidad de comprender cómo algunos hombres y mujeres intentaron dar sentido a un evento histórico que todavía hoy persiste en la memoria nacional. Seguramente fueron muchos más los mensajes enviados (es difícil calcular cuántos se han perdido), pero sin duda su número palidece si lo ponemos en relación con las diez a doce mil cartas que, según su secretaria, Eva recibía cada día. ${ }^{6}$ En una población con cerca de 16 millones de habitantes registrados en el censo nacional de población de 1947, quienes tuvieron la iniciativa de escribir fueron excepcionales. La rapidez con que fueron escritas —el 90\% entre el 27 de julio y el 11 de agosto - la gran diversidad de mensajes que contienen y el hecho de que muchos de sus firmantes fueran al velorio y participaran en distintas ceremonias fúnebres sugieren que las actitudes ante la muerte estaban asociadas también con el acto de escribirla. ${ }^{7}$ En las formas y significados posibles de esta escritura se interesa este artículo.

Los obituarios y necrológicas publicados en la prensa y, más recientemente, los muros virtuales de una persona que murió, y que mantienen activos sus familiares o amigos, han sido objeto de múltiples análisis. En general son pensados como un medio para reconocer la pena del círculo íntimo del difunto y como una oportunidad para el emisor de expresar la propia. ${ }^{8}$ Los telegramas y notas de pésame estudiados en este artículo pueden ser interpretados en esta doble dimensión y ofrecen, en su especificidad, una ventana para ver el luto y el involucramiento de la sociedad con la muerte. Para comprender estos escritos, buceo en oraciones, palabras y frases que nombran emociones en las que se involucran objetos, situaciones, personas. El artículo analiza también la expresión no verbal de las emociones y busca captar

6. Nicholas Fraser y Marysa Navarro, Evita: The Real Life of Eva Perón (Nueva York: W. W. Norton \& Company, 1996) 117.

7. La información de los 388 telegramas y las 180 tarjetas de pésame se volcó a una base de datos que contiene información sobre hora, día y lugar de emisión y recepción, así como el nombre, apellido, sexo y profesión del remitente. También se recopiló información sobre la materialidad de cada telegrama y tarjeta (tipo de papel y de escritura), las maneras en que aparece mencionada Eva Perón y el texto completo del mensaje. Cada uno de los textos fue analizado por sí mismo y en relación con los demás y todos se contrastaron con otras narrativas sobre la muerte y el dolor que circulaban en distintas expresiones de la cultura de masas y del saber médico.

8. Armando Petrucci, Writing the Dead. Death and Writing Strategies in the Western Tradition (Stanford: Stanford University Press, 1998) 121-122; Kathleen McElroy, "You Must Remember This: Obituaries and the Civil Rights Movement", Journal of Black Studies 44.4 (2013): 335-355; Michael Brennan, "Condolence Books: Language and Meaning in the Mourning for Hillsborough and Diana", Death Studies 32.4 (2008): 326-351. 
cómo se interrelacionan las normas, las expresiones y los intentos de comunicar experiencias emocionales. ${ }^{9}$

La muerte estimula lenguajes emocionales que son indisociables de sus contextos social, cultural y político específicos. Los mensajes que dan sentido a estas páginas se originaron por el fallecimiento de la mujer más poderosa de la Argentina, por ello, estos textos sugieren algunas características del componente emocional que, al ser inseparable del ideológico, definía el vínculo con el peronismo.

El argumento general es que en los telegramas y las notas de pésame se repitieron frases estandarizadas y protocolares de pésame vinculadas con las normas sociales, algunas buscaron ajustarse a normas emocionales que aspiraban a fijar qué y cómo sentir, y otras fueron grandes conversaciones entre una comunidad de hombres y mujeres diversos que evaluaron la importancia del acontecimiento y buscaron expresar cómo vivieron y sintieron la muerte de la líder. Por supuesto que no fue la única conversación: la exhibición y expresión pública de emociones generó una corriente subterránea, y no tanto, de antipatía, rabia y tedio entre aquellos que se negaron a llorar. Ambas conversaciones se referenciaron mutuamente y se filtraron, a través de supuestos y silencios, en telegramas y tarjetas de pésame sugiriendo relaciones estrechas entre fidelidades políticas y el derecho al dolor. Estos breves textos muestran que una comunidad política es también una comunidad emocional, en la cual se privilegian unas emociones por encima de otras y algunos vínculos por sobre otros, y sugieren que las emociones políticas cobran sentido en la confluencia de trayectorias individuales, construcciones sociales y culturales de significado e interacciones con el poder.

\section{Telegramas y tarjetas de pésame}

La noticia de la muerte de Eva Perón, anunciada oficialmente por la radio del Estado el 26 de julio de 1952, movilizó a la población de maneras muy diversas. Las multitudes se congregaron en las calles de las ciudades, los templos, la plaza principal de cada localidad y en las sedes de los gobiernos locales. Altares en las esquinas, en los domicilios particulares y manifestaciones con la imagen de la extinta acompañaron todo el proceso ritual, como era habitual en los funerales públicos de la Argentina contemporánea. Las sedes sindicales y las unidades básicas desperdigadas por toda la Argentina fueron también el espacio para expresar el duelo, así como el recinto adonde acudir para recibir las directivas sobre las formas del luto. Rápidamente estas estructuras organizativas vitales del gobierno peronista se adhirieron a los honores y disposiciones oficiales y buscaron encauzar la congoja colectiva: sincronizaron de manera espectacular las ceremonias

9. Rob Boddice, The History of Emotions (Manchester: Manchester University Press, 2018); Javier Moscoso Sarabia, "De la Historia de las Emociones a la Historia de la Experiencia. Los dibujos y notas de un marino español durante la Guerra Civil", La cultura de las emociones y las emociones en la cultura española contemporánea (siglos XVIII-XXI), eds. Luisa Elena Delgado y otros (Madrid: Cátedra, 2018) 215-234. 
locales con la realizada en la capital federal, mandaron "representantes" al velorio de Buenos Aires, "se encargaron de enviar telegramas" y acopiaron telegramas de terceros. $^{10}$

La expansión de la red de infraestructura ferroviaria, especialmente a partir de la primera década del siglo XX, provocó un aumento considerable en la cantidad de telegramas enviados en el espacio doméstico. ${ }^{11}$ Con el tendido de cables, que iban pegados a las vías del ferrocarril, las cuales se hicieron más anchas y largas, fue mucho más fácil enviarlos. Su incremento fue significativo a partir de 1908 y desde esa fecha no dejó de crecer. Casi en paralelo, también desde el Estado se intentaba construir edificios para el área de telecomunicaciones. En los años 30 este proceso cobró impulso y con el peronismo sufrió un salto, al ser parte de los planes quinquenales del gobierno. Entre 1947 y 1948 se proyectaron, licitaron, adjudicaron y se inició la construcción de 80 edificios de Correos y Telecomunicaciones; entre 1933 y 1946, se habían construido $60 .{ }^{12}$ Estos edificios eran de correos, telégrafos y radio y encarnaban la innovación, eficiencia y racionalidad a tono con la planificación estatal. Aunque estaban distribuidos de modo dispar en el territorio nacional, y si bien los "servicios de telegrafia" continuaron expandiéndose en el curso de la década e incluso después, el telegrama era un medio de transmisión de noticias muy relevante en los años 50. Fue lógico que también se escribieran por la muerte de Eva. Algunos periódicos reprodujeron el listado de aquellos que fueron enviados a Buenos Aires por las organizaciones peronistas, y comentaron "la innumerable correspondencia" que esas mismas organizaciones recibían. ${ }^{13} \mathrm{El}$ salto hacia adelante de los mensajes de pésame entre julio y agosto de 1952 es todavía recordado por los trabajadores postales. ${ }^{14}$ Sin embargo, el sesgo geográfico del archivo es notable. El 80\% de los telegramas consultados se enviaron desde la capital de la república, y la mayoría de los restantes, desde distintas localidades de la provincia de Buenos Aires. En las grandes ciudades y en las pequeñas localidades del interior se enviaron a las unidades básicas o a las sedes locales del Partido Peronista Femenino o del Partido Peronista; fueron estos últimos quienes los acopiaron y los remitieron a la Subsecretaría de Informaciones del Estado. En ese tránsito, sin

10. Zavalia Valverdi, La Gaceta (Tucumán) 30 de agosto de 1952: 1. Agradezco a Lucía Santos Lepera haberme facilitado la información.

11. Arish Tatiana González, "Economic Disparity Yet Resulting Similarity: The 'Double Paradox' of Argentina's and Mexico's Electric Telegraph and Telephone Difusion, 1851-1997” (Tesis de doctorado en Filosofia, London School of Economics and Political Science, 2010); Lila Caimari, "Derrotar la distancia. Articulación al mundo y políticas de la conexión en la Argentina, 18701910”, Estudios Sociales del Estado 5.10 (2019): 153-154.

12. Collado 33.

13. La Gaceta (Tucumán) 30 de julio de 1952: 2. Según el periódico, se habrían enviado 7 mil telegramas de condolencias "solo en la cabecera del distrito 16", en Tucumán, y "un promedio de 1500 (telegramas) por día”. La Gaceta (Tucumán) 1 de agosto de 1952: 3.

14. Realicé tres entrevistas a trabajadores postales que se desempeñaron durante los años 50 en tres localidades del interior del país y coinciden en "lo impresionante que fue cuando murió Eva" (expresión de Darío), entrevista telefónica, 13 de mayo de 2020. 
duda, muchos se perdieron, y es el azar de la conservación, muy probablemente, el que explica la distorsión geográfica de dichos mensajes. ${ }^{15}$

Fieles a su estructura originaria, que, desde mediados del siglo XIX, exigía tres datos: destinatario, origen y asunto; es decir, una brevísima descripción del motivo del mensaje, la inmensa mayoría de los que se han conservado fueron escritos a máquina. Comparten el mismo papel transparente y, curiosamente, casi no los hay con la franja negra sobre el lado superior izquierdo, la cual podía ser parte del mensaje de duelo. Las "tarjetas de pésame"16 fueron escritas a mano y son más heterogéneas en su procedencia geográfica. Son una adaptación de la "carta de visita" usada por las élites desde el siglo XIX, que ya contaba con los datos del emisor cuidadosamente impresos. Se observa, en ambos soportes, la democratización de la muerte escrita para las mujeres, quienes participan casi tanto como los hombres con mensajes breves por la muerte de Eva. ${ }^{17}$

El parentesco entre los telegramas y las notas de pésame en su formulación textual es claro. ${ }^{18}$ Frases, expresiones y palabras se repiten en ambos y delatan un espesor temporal que los remonta al epistolario privado del siglo XIX. "Sentido pésame", o su variante, "mi más sentido pésame" fueron tan usuales como genéricas. También "transmita al señor presidente y reciba mi sentido pésame" integró el stock de formulismos disponibles. ${ }^{19}$

Este conservadurismo, siguiendo a Armando Petrucci, se debe a que resultaba práctico y fácil de comunicar. Se comprende, entonces, como una expresión acorde a la convención social dominante. Desde el siglo XVIII, los manuales de cortesía educaban a las clases altas para la muerte; cómo enfrentarla y cómo comportarse

15. También es probable que nunca hayan llegado a Buenos Aires o que se hayan perdido luego del golpe de Estado del 16 de septiembre de 1955.

16. En este artículo uso indistintamente nota de pésame o tarjeta de pésame.

17. De la información disponible se desprende que 154 hombres y 113 mujeres escribieron mensajes individuales; de ellos, 30 lo hicieron en nombre propio o de su cónyuge, y 34 lo hicieron en nombre de un grupo integrado por tres o más personas, generalmente organizaciones o corporaciones. Es diferente a lo que observa Michael Brennan para el caso de Gran Bretaña y en los libros que se habilitaban en las iglesias, en donde son las mujeres quienes escriben en nombre propio y de sus esposos los mensajes de condolencias. Lo explica como una extensión al espacio público del trabajo emocional que realizan las mujeres. Brennan 331.

18. Su contenido es similar al de los avisos fúnebres y a los escritos que por el Día de los Muertos se publicaban en los periódicos.

19. La primera expresión corresponde a un telegrama firmado por Edmundo Ribero, Buenos Aires, 29 de julio de 1952, caja 5. Una economía expresiva similar: "Ruégole transmita pésame al señor presidente", firmado por Tina Elba, 28 de julio de 1952. AGNA, Buenos Aires, Archivo Intermedio, Secretaría Legal y Técnica de la Presidencia de la Nación, Fondo Fiscalía Nacional de Recuperación Patrimonial, Comisión 21, caja 5. En algunas ocasiones pude seguir la repetición, posiblemente alentada por el empleado postal que es uno de los mediadores de estos mensajes. Por ejemplo, desde la sucursal 2 de Capital Federal se emitieron dos telegramas idénticos y seguidos, el 1276 y 1277, receptados por el empleado Rojo. AGNA, Buenos Aires, Archivo Intermedio, Secretaría Legal y Técnica de la Presidencia de la Nación, Fondo Fiscalía Nacional de Recuperación Patrimonial, Comisión 21, caja 6. 
cuando le sucedía a otro eran parte de su educación social y emocional. Más tarde, y a través de la escuela pública, las niñas y los niños de la Argentina de las primeras décadas del siglo XX podían leer en los libros escolares referencias permanentes a la muerte, sobre qué hacer y qué sentir cuando se moría el abuelo o cómo actuar en un velorio. La capacidad de decir lo correcto a la persona indicada en el momento adecuado es una habilidad social. La muerte también tiene sus reglas y, como sostuvo hace mucho tiempo Marcel Mauss, el llanto y las expresiones orales de los sentimientos son fenómenos sociales caracterizados por la no-espontaneidad y por la obligación más perfecta. ${ }^{20}$ No se manda un telegrama o una tarjeta de pésame para criticar al muerto. "Sentido pésame" bastaba para dar una respuesta socialmente adecuada ante la pérdida, una frase mínima que cumplía también con las expectativas del gobierno. Durante todo el proceso ritual, el gobierno facilitó que la población se involucrara en el evento. También ejerció su poder de coacción; la participación ciudadana en un velorio que había preparado con denuedo era una forma de tomar el pulso de su vínculo con el peronismo en una coyuntura política y social muy conflictiva. Las frases "ante la duda no haya recibido la anterior", "por las dudas se haya perdido o no haya llegado a usted" podían acompañar también a la fórmula de pésame. Es coherente, por ejemplo, con la obligatoriedad de llevar un brazalete negro como señal de luto en todos los espacios públicos y establecimientos escolares que decretó el gobierno en julio de 1952. Para los afiliados y militantes peronistas hubo también otras exigencias como, por ejemplo, usar luto en la solapa durante 30 días y asistir a los actos oficiales de duelo. La intención de que "el pésame llegue a manos del general" hizo que Horacio Priani, Alberto du Bois y Arturo García Portela, directivos de la empresa cinematográfica Alfa, enviaran dos veces la misma nota de pésame. Como explican claramente al inicio del texto:

Ante la omisión de nuestros nombres en las publicaciones efectuadas con motivo de las expresiones de condolencias enviadas al excelentísimo señor presidente y suponiendo que la nota que enviamos oportunamente no llegó a destino nos permitimos sustraer la atención del señor subsecretario de informaciones y prensa solicitando una vez más sus buenos oficios para que nuestro pésame, cuyo texto repetimos a continuación, llegue a manos del general. ${ }^{21}$

La "preocupación" de estos empresarios del cine se entiende mejor en el marco de las complejas y tensas relaciones entre el peronismo y "el mundo del espectáculo". El vínculo entre ambos se forjó tempranamente y, si bien Perón integró a los artistas a su proyecto cultural cuando asumió el poder, también la irrupción del

20. Marcel Mauss también indicaba que el formalismo y la adecuación a la norma social no indica que la persona no sienta lo que dice que siente. Marcel Mauss, "L'expression obligatoire des sentiments (rituels oraux funéraires australiens)", Journal de Psychologie 18 (1921): 8. Traducción propia.

21. Horacio Priani, Alberto du Bois y Arturo García Portela, Buenos Aires, 13 de agosto de 1952, caja 6. Ejemplos similares, AGNA, Buenos Aires, Archivo Intermedio, Secretaría Legal y Técnica de la Presidencia de la Nación, Fondo Fiscalía Nacional de Recuperación Patrimonial, Comisión 21, caja 457. 
movimiento político que lideró polarizó desde el inicio a las actrices, los actores, los directores y los propietarios de medios. ${ }^{22}$ Esta "época de oro", en la que, por ejemplo, cada emisora de radio era una exultante fuente laboral que le daba trabajo a un promedio de 400 personas, fue también de "plomo" para otros integrantes del campo artístico y opositores políticos. ${ }^{23}$ En 1952, la polarización y las tensiones se habían profundizado en el marco de un gobierno acusado de autoritario y una nota de pésame podía ser una respuesta a la coacción estatal.

Si bien la industria cinematográfica no era controlada abiertamente por el gobierno, tampoco rechazó los beneficios proteccionistas que este le ofrecía. ${ }^{24}$ Sugestivamente, entre quienes explicitaron sus profesiones en los mensajes de condolencias, el 26\% estaba vinculado con la industria del entretenimiento (directores, productores, compañías, cantantes, bailarinas, actrices, directores, etcétera), y la inmensa mayoría de quienes escribieron en representación de organizaciones pertenecían al cine o al teatro. En envío de una nota de pésame fue un recurso para disipar sospechas de disidencia con quien se esperaba obtener beneficios económicos.

Estos breves textos pueden pensarse también como una expresión emocional. Es decir, una misma oración y frases idénticas pueden haber sido usadas con la intención de expresar emociones. Además, un telegrama salía al menos dos veces más caro que una carta y se cobraba por palabra; el costo, más que la norma social, dictaba la economía expresiva. La frase "sentido pésame", que coloca el complemento indirecto después del verbo y no adelante (me pesa), alberga en sí misma una intención emocional, al expresar que a la persona "le pesa" la muerte de quien falleció. Mediante su uso se expresaba una norma emocional que definía qué se debía sentir y cómo debía expresarse lo que se sentía en esa circunstancia específica. ${ }^{25}$ Se la decía personalmente a los deudos, o se la escribía mediante telegramas y tarjetas de pésame, en el transcurso del ciclo ritual o inmediatamente después. Era una norma emocional legítima para un periodo temporal específico. A pesar de su performatividad, no todos usaron exactamente la misma norma. Se apeló también a técnicas para intensificar actitudes, especialmente a través del subrayado o la mayúscula, o a técnicas de amplificación como "con profunda pena e inconmensurable tristeza". ${ }^{26}$

"Ante la irreparable pérdida de EVA PERON me adhiero a tu congoja y comparto de todo corazón el inmenso dolor que se te ha causado. Un estrecho

22. Yanina Andrea Leonardi, “Teatro y políticas públicas durante el primer peronismo”, Peronismo y representación: escritura, imágenes y políticas del pueblo, comp. Carina González (Buenos Aires: Final Abierto, 2015) 159-179.

23. Carlos Ulanovsky, Días de radio: historia de la radio en Argentina (Buenos Aires: Espasa Calpe, 1995) 206.

24. Clara Kriger, Cine y peronismo: el Estado en escena (Buenos Aires: Siglo XXI Editores, 2009).

25. Arlie Russell Hochschild, "Emotion Work, Feeling Rules and Social Structure”, American Journal of Sociology 85.3 (1979): 551-575.

26. J. R. Martin y David Rose, Working with Discourse: Meaning Beyond the Clause (Londres / Nueva York: Continuum, 2003). 
abrazo". ${ }^{27}$ La proximidad mediante el tuteo y el gesto fraterno de abrazarlo, habitual en la correspondencia con el gobierno peronista, cobra pleno sentido a partir del dolor. La historiadora Barbara Rosenwein propone tener en cuenta cuán importante es una emoción en relación con otras en un tiempo dado. Considerar qué palabra nombra una emoción es importante, sostiene, en la medida que nos permite captar el peso de las palabras y las frases para establecer su importancia relativa. ${ }^{28}$ "Dolor" fue la palabra clave, y mantiene a su vez una relación estrecha con el término "condolencia", que deriva de la acción "condolerse", es decir, "compartir un dolor", el cual solía emplearse en plural ("condolencias") para referirse a la participación en un dolor ajeno. "Mis condolencias" aparece en telegramas y tarjetas de pésame, pero si, siguiendo a Rosenweim, se analizan la frecuencia, las palabras que articulan las frases y cuáles aparecen asociadas con el sentir individual, se advierte que la palabra hegemónica para comunicar la emoción por la muerte fue "dolor". Fue una palabra que también el peronismo reclamó para sí y que integró tempranamente a su discurso político. No solo se diferenció del orden liberal previo para denunciar su corrupción política y económica, sino también su inhumanidad. ${ }^{29}$

A partir de 1945, lo hizo a través de Eva quien, además, no cesó de repetir su vocación de "mitigar el dolor" de los humildes. Con esta frase, Eva se apoderaba y empoderaba los dolores populares, pues, como sostiene Joanna Bourke, enunciar cuál dolor es auténtico es una cuestión de poder. ${ }^{30}$ Su propio dolor físico y las intervenciones a su cuerpo para aliviarlo fueron parte de las conversaciones y especulaciones públicas que acompañaron su agonía y estimularon la movilización y vigilia colectiva. Más aún, desde la retórica oficial, el dolor de Eva y su posterior muerte fueron presentados como pruebas de su sacrificio para redimir el dolor popular. Como se ha mostrado en otro trabajo, Eva construyó su rutilante carrera política acompañada de un discurso emocional y una política de las emociones en las que el dolor ocupó un lugar central. ${ }^{31}$

Con sus variantes expresivas, como la pena, el llanto, los sollozos y las lágrimas; el dolor y sus metáforas también eran parte del lenguaje popular y de las formulaciones de la cultura de masas. ${ }^{32}$ Los folletines, los melodramas, los boleros, el tango,

27. Carlos Feilberg, Buenos Aires, 27 de julio de 1952, caja 7. El telegrama está dirigido al subsecretario de Informaciones del Estado, Raúl Apold.

28. Barbara H. Rosenwein, "Problems and Methods in the History of Emotions", Passions in Context I 1 (2010): 15 .

29. Mark Healey, El peronismo entre las ruinas: el terremoto y la reconstrucción de San Juan (Buenos Aires: Siglo XXI Editores, 2012).

30. Joanna Bourke, The Story of Pain. From Prayer to Painkillers (Nueva York / Oxford: Oxford University Press, 2014) 72.

31. Sandra Gayol, "La otra cara de la felicidad: dolor y martirio en el peronismo clásico", Anuario del Instituto de Historia Argentina 20.1 (2020): e110, doi: 10.24215/2314257Xe110.

32. También en los avisos fúnebres de los periódicos de la época primaban las palabras "dolor" y "pésame". 
los radioteatros y el cine eran un "diccionario y una gramática de la sentimentalidad" 33 que, además de ser utilizada por el gobierno peronista, ofrecía guiones para la educación emocional de la población. En una bella construcción poética, que parece arrancada de un bolero, los Arrieta envían un telegrama al subsecretario de Informaciones del Estado, Raúl Apold: "Hubiera querido hallarte en estos momentos para depositar en ti este dolor que sentimos". ${ }^{34}$ Una intención similar de escribir lo que siente, pero con un impacto más visible de la propaganda oficial, manifestó José Cabral. Su impulso de escribir, confesó, es:

Un sincero imperativo que fluye de lo más íntimo de mi alma: expresarle mi profundo sentimiento de incontenido dolor, por el fallecimiento de la señora EVA PERON, protectora de los humildes y que abrió nuevas luces para el pueblo de la patria. Por eso y porque sé de su amistad creo mi deber enviarle la presente carta.

El historiador William Reddy llamó emotives a las expresiones afectivas que representan el intento de un individuo de traducir sentimientos internos a través de convenciones culturales. Los emotives son construcciones, creaciones que intentan decir lo que se siente; no son solamente emisiones lingüísticas, sino que crean al decir, y es allí, sostiene Reddy, donde se produce asimismo la navegación de las emociones. Es lo que hicieron los Arrieta y Cabral y también, por ejemplo, Iris Marga. La "gran dama del teatro", como se le conoció, apeló a distintos soportes materiales y expresiones afectivas para intentar comunicar su experiencia emocional por la muerte de Eva. La actriz fue copartícipe del telegrama de pésame enviado por la Asociación Argentina de Actores y, como vocal del Ateneo Eva Perón, asistió —y posiblemente participó en los preparativos - al funeral que el Ateneo tributó a la extinta en la iglesia de La Merced de la ciudad de Buenos Aires. ${ }^{35}$ También fue al velorio el 30 de julio, y el 1 de agosto envió una carta al subsecretario Apold. Escrita a mano, con tinta azul y letra muy cuidada, la epístola inicia con una duda que deviene en una afirmación. Tras una escritura formal en el encabezado, por el uso de "Don" y "mi estimado", prosigue:

Muchas veces en el transcurso de mi vida (tenía 51 años) me he preguntado si no sería mejor dar rienda suelta a los propios impulsos saltando por sobre todos los protocolos establecidos. Hoy pienso que, si así lo hubiera hecho ayer, cuando lo vi de lejos (en el velorio), y me hubiera confundido en un estrecho abrazo con Ud., nadie podría condenar el que yo buscara en su amistad sincera y buena mitigar este dolor que no cede, esta falta de resignación que no llega.

33. Martín Kohan, Ojos brujos: fábulas de amor en la cultura de masas (Buenos Aires: Ediciones Godot, 2018) 10.

34. Santiago, Isabel y Nilda Arrieta, Buenos Aires, 30 de julio de 1952. AGNA, Buenos Aires, Archivo Intermedio, Secretaría Legal y Técnica de la Presidencia de la Nación, Fondo Fiscalía Nacional de Recuperación Patrimonial, Comisión 21, caja 5.

35. "El Ateneo cultural femenino hizo oficiar un funeral por Eva Perón", Radiolandia (Buenos Aires) 16 de agosto de 1952. 
La autocontención en sus conductas y expresiones emocionales no le ahorró, según ella misma escribe, la experiencia del arrepentimiento. Según el protocolo impuesto por el Estado, únicamente los arrebatos que desafiaban las estrictas medidas de seguridad permitían la proximidad con los funcionarios y Marga no lo intentó, lo que le impidió el abrazo y la interacción corporal y emocional con el subsecretario de Informaciones. Recurrió, entonces, a la escritura, a ciertas formas y énfasis que nombraran, comunicaran y produjeran, diría Monique Scheer, una experiencia emocional. ${ }^{36}$

Luego de compartir con Apold su "dolor que no cesa", pide disculpas por las "deshilvanadas palabras". Sin embargo, el "desorden”, como califica a su escritura tal vez por su estado emocional, no la inhibe de usar "palabras tan simples como tan verdaderas". Desea que el subsecretario, cuyo dolor da por sobreentendido, pues lo considera un deudo, "¡alcance el consuelo necesario para seguir adelante con la obra! Ella así lo querría. Ella así lo quiere, porque para nosotros Ella no fue. Es y será para toda la vida. Suya”.

Iris Marga apela a un amplio repertorio de palabras emocionales, de gestos corporales, de acciones y de situaciones a través de las cuales busca una adecuación entre lo que dice y lo que siente. La actriz va más allá. Seguramente al tanto de la recientemente creada Asociación Amigos de Eva Perón, destinada a "perpetuar su memoria", le asigna a Apold el liderazgo y la responsabilidad de seguir, a través de la nueva organización, "adelante con su obra". En un gesto habitual ante la muerte, en la que el difunto orienta y dictamina las acciones de los vivos, "Ella" (la apelación a la tercera persona del singular, la mayúscula y el subrayado está en el original y es muy significativa) lo quiere y es y será. Marga descuenta la perpetuidad del recuerdo, tan eterno como definitivo. ¿Para quiénes?

\section{Dolor peronista}

Tanto en los mensajes de individuos como de organizaciones, la filiación política con el peronismo en general no aparece explicitada. Iris Marga, vimos, apela al dolor del "nosotros" que no se limita, obviamente, al destinatario directo del mensaje. Ángel escribe que "como buen argentino llora la muerte de Eva". ${ }^{37}$ También Julio asevera que "a los buenos argentinos solo nos queda el consuelo de pensar en que Evita desde el cielo continuará velando por su querido pueblo" ${ }^{38}$

Los "buenos argentinos" trazaban con la escritura los límites de la comunidad en duelo que, se sostenía, compartía las mismas emociones por la pérdida. Ni en

36. Monique Scheer, "Are Emotions a Kind of Practice (and Is That What Makes Them Have a History)? A Bourdieuian Approach to Understanding Emotion”, History and Theory 51.2 (2012): 193-220.

37. Angel Fassi, Buenos Aires, 9 de agosto de 1952. AGNA, Buenos Aires, Archivo Intermedio, Secretaría Legal y Técnica de la Presidencia de la Nación, Fondo Fiscalía Nacional de Recuperación Patrimonial, Comisión 21, caja 2.

38. Julio Sojo (h), 6 de agosto de 1952. AGNA, Buenos Aires, Archivo Intermedio, Secretaría Legal y Técnica de la Presidencia de la Nación, Fondo Fiscalía Nacional de Recuperación Patrimonial, Comisión 21, caja 2. 
los telegramas ni en las tarjetas de pésame, que buscan comunicar una experiencia emocional, se percibe un llamamiento a una comunidad de dolientes que, en su expresión abstracta, podría equipararse con toda la nación. No es la nación argentina en duelo público y sacudida por la muerte de una "gran mujer" la que aparece en los escritos. A contrapelo de las narrativas oficiales que entre julio y agosto batallaron con la idea de la "comunidad nacional en duelo público", 39 hay expresiones de pésame que no tienen ninguna pretensión integradora. Mas aún, el "sentido pésame" generalizado aparece bajo sospecha por falto de sinceridad o por mero oportunismo.

El engaño emocional era una de las discusiones políticas en la Argentina de entonces. Los opositores al peronismo también denunciaron simulación emocional. En realidad, la interrogación sobre el engaño emocional en las multitudes está en el origen de los primeros estudios de las emociones políticas que vieron la luz en el recambio del siglo XIX al XX con el advenimiento de la sociedad de masas. Los fascismos europeos de entreguerras y la experiencia soviética revitalizaron la mirada negativa hacia las emociones colectivas que fueron asociadas con los totalitarismos. ${ }^{40}$ Américo Ghioldi ofreció la versión vernácula más explícita de este esquema. Desde Montevideo, donde pasaba su exilio, contempló con "furia y pena" las expresiones fúnebres de la Argentina de 1952. No dudó en afirmar que era el "totalitarismo peronista" el que manipulaba las expresiones emocionales y, obviamente, que el régimen democrático que decía defender, al garantizar las libertades, es el que permite el compromiso consciente de sus ciudadanos, plenamente responsables de sus deberes y de sus emociones. ${ }^{41}$ Para los contemporáneos opositores, Juan Perón podía aparecer como un manipulador emocional, pero era Eva la principal meneuse de foule y quien manejaba las emociones propias y ajenas con maestría. A su vez, y desde que irrumpió en la arena política a partir de su vínculo amoroso con Perón, se denunciaban sus desbordes emocionales - cual "simple histérica"-, que habrían llegado al paroxismo durante su agonía. Sus "aullidos de dolor" en su lecho agonizante, que fueron correspondidos por el "monstruo que aulló de dolor" durante su funeral, ${ }^{42}$ habían sido parte de los chismes, rumores y versiones que circularon oralmente por toda la Argentina semanas antes de su muerte. A estas descripciones de imitaciones lingüísticas no discursivas, a estas onomatopeyas asociadas con los animales salvajes que habría provocado su cáncer, se oponían los "buenos argentinos". El "nosotros" de las notas de pésame tiene como trasfondo estas narraciones clasistas y sexistas que son contrarrestadas a partir del vínculo afectivo, "auténtico" se dirá, con Eva.

Las emociones, sostiene Martha Nussbaum, no son simples impulsos, sino que incluyen valoraciones que tienen un contenido evaluativo, implican juicios y generan

39. Puede consultarse la cobertura realizada por los periódicos oficialistas durante y después del velatorio y funeral.

40. Véase María Bjerg, "Una genealogía de la historia de las emociones”, Quinto Sol 23.1 (2019): 1-20, doi: 10.19137/qs.v23i1.2372.

41. Américo Ghioldi, El mito de Eva Duarte (Montevideo: Compañía Impresora S.A., 1952) 17.

42. Ricardo Boizard, Esa noche de Perón (Santiago de Chile:Teatinos, 1955) 72. 
vínculos entre las personas. ${ }^{43}$ Sentir dolor, por ejemplo, significa atribuir la palabra "dolor" a lo que se siente y puede estar vinculado a una persona, un objeto, una situación. La relación es activa y reflexiva y, se puede agregar, positiva. Juan Pedro Martínez, "profundamente dolorido" por la muerte de "la infinitamente amada Evita", aprovecha la nota de pésame para afirmar que "seguirá trabajando como peronista en una acción armónica y exclusiva del cerebro conectado con el corazón...". ${ }^{44} \mathrm{El}$ diminutivo Evita, muy usado en estos documentos, suele ser precedido por el "infinitamente amada", "amadísima", "siempre querida" o "muy amada". Esta forma de enunciación transmite la proximidad y acorta las distancias en un vínculo desigual; son frases y expresiones que amplifican e intensifican la comunicación de una experiencia emocional, pero que también dejan afuera a quienes no la amaron. El dolor era posible y pensable entre "quienes la quisimos de verdad". ${ }^{45}$

Si bien el dolor nunca es universal, interactúa con determinadas situaciones y con otras emociones. No existe independientemente de otras prácticas del yo: cognitivas, perceptivas, emocionales, evaluativas, que están entrelazadas con el contexto que respalda o desconoce conductas asociadas con "estar en dolor / estar dolorido". ${ }^{46}$ El grafiti "Viva el cáncer", estampado en una pared cerca de la residencia donde Eva agonizaba, y escrito días previos a su muerte, se acopló al cotilleo y los rumores que siempre acompañaron su figura. La ira usada por los antiperonistas para describir lo que se entendía como "el desorden emocional de Eva”, así como para etiquetarla a ella y a quienes integraban su círculo estrecho; junto con el odio presente en el horizonte emocional de los opositores hacia el peronismo, son los interlocutores silenciosos de estas frases. Si tanto la odiaron, ¿cómo van a sentir dolor por su muerte? La pérdida era para el peronismo y el dolor también era peronista. "Seguimos sin poder reponernos del tremendo golpe que ha enlutado a la nueva argentina justicialista. ${ }^{47}$

La "nueva Argentina justicialista" de 1952 estaba en plena ebullición y la muerte de Eva no la interrumpió. La exclusividad del vínculo político que se intensificó desde inicios de los años 50 tendió a inhibir otras vinculaciones y alentó por ello deserciones. Los otrora peronistas pasaron a integrar, en palabras de Loris Zanatta, una inmensa zona gris en los márgenes del régimen. Quienes se habían

43. Martha C. Nussbaum, Las emociones politicas. ¿Por qué el amor es importante para la justicia? (Barcelona: Paidós, 2014) 19.

44. Juan Pedro Martínez, profesor universitario, oficial técnico de la gobernación, Entre Ríos, 2 de agosto de 1952. AGNA, Buenos Aires, Archivo Intermedio, Secretaría Legal y Técnica de la Presidencia de la Nación, Fondo Fiscalía Nacional de Recuperación Patrimonial, Comisión 21, caja 8.

45. Julio Giménez Salvatierra, desde Pozo de Tigra, s.f. AGNA, Buenos Aires, Archivo Intermedio, Secretaría Legal y Técnica de la Presidencia de la Nación, Fondo Fiscalía Nacional de Recuperación Patrimonial, Comisión 21, caja 15.

46. Bourke 9 .

47. José María Contursi, Buenos Aires, 6 de agosto de 1952. AGNA, Buenos Aires, Archivo Intermedio, Secretaría Legal y Técnica de la Presidencia de la Nación, Fondo Fiscalía Nacional de Recuperación Patrimonial, Comisión 21, caja 2. 
ido tampoco podían sentir dolor pues este no era una experiencia emocional posible entre quienes "la amaron de apariencia". ${ }^{48}$ Muerta "desde el cielo ahora reirá a quienes desinteresadamente la amábamos y reverenciáramos". ${ }^{49}$ El dolor exige exclusividad amorosa y política. No encuentra el contrapunto aquí en la primacía de otras emociones, como, por ejemplo, el odio opositor. "Quienes no han sentido ni sienten el verdadero amor hacia la Jefa espiritual", escribe Rosario M. Ceriani en la carta que acompaña el telegrama de pésame, no deben pertenecer al peronismo ni participar en las ceremonias fúnebres. ${ }^{50}$

Asimismo, Miriam Stewart pide en su telegrama: "Hágale saber al Sr Presidente que como siempre identificado con sus ideales hoy también lo estoy con su dolor". ${ }^{51}$ Si las ideas políticas arraigan o no dependiendo de la carga afectiva generada al entrar en contacto con ellas, ${ }^{52}$ también fue la fidelidad con las ideas políticas la que contribuyó a nutrir el "derecho al dolor".

La interacción discursiva y el juego de espejos entre los peronistas de siempre, los otrora peronistas y quienes nunca fueron peronistas se disparó con la muerte y el funeral de Eva Perón. Su desaparición física no solo no opacó su figura, sino que nutrió y fortaleció la comunidad emocional peronista. El peronismo era el partido en el gobierno, pero también una comunidad emocional cuyo "sistema de sentimientos" representaba lo que la comunidad y los individuos que la integran definen y consideran como significativo o peligroso para ellos, las evaluaciones que hacen de las emociones de los otros, la naturaleza de los lazos afectivos entre las gentes que reconocen, y los modos de expresión de las emociones que esperan, propician, toleran, deploran. ${ }^{53} \mathrm{La}$ muerte realzó la importancia de la emoción del dolor, buscó fijar quiénes podían sentirlo y cómo, así como también deslindar a quienes quedaban excluidos de la comunidad emocional peronista.

\section{La intensidad del dolor}

A pesar de la constricción expresiva impuesta por la brevedad del mensaje, quienes escribieron no declinaron en intentar cuantificar el dolor emocional. Como

48. Pedro González, s.f. AGNA, Buenos Aires, Archivo Intermedio, Secretaría Legal y Técnica de la Presidencia de la Nación, Fondo Fiscalía Nacional de Recuperación Patrimonial, Comisión 21, caja 9.

49. C. Cornero Latorre, tarjeta escrita a mano, s.f. AGNA, Buenos Aires, Archivo Intermedio, Secretaría Legal y Técnica de la Presidencia de la Nación, Fondo Fiscalía Nacional de Recuperación Patrimonial, Comisión 21, caja 6.

50. Rosario M. Ceriani, 31 de julio de 1952, tarjeta escrita a máquina.AGNA, Buenos Aires, Archivo Intermedio, Secretaría Legal y Técnica de la Presidencia de la Nación, Fondo Fiscalía Nacional de Recuperación Patrimonial, Comisión 21, caja 38.

51. Miriam Stewart, alias Sarita Vivo, Buenos Aires, 9 de agosto de 1952, telegrama a máquina, caja 38.

52. Deborah, Gould, “On Affect and Protest”, Political Emotions. New Agendas in Communication, eds. Janet Staiger y otros (Nueva York: Routledge, 2010) 33.

53. Rosenwein 11. 
sostiene Boddice, el dolor es, en el mejor de los casos, una etiqueta confusa. Describe al mismo tiempo una apariencia o superficie, un estado interno, fisiológico y neurológico, y la recepción de ambos tal como los proyecta otro. ${ }^{54}$ Polivalente y multidimensional, desde por los menos el siglo XVIII hubo intentos de alinear sensibilidades diferenciales al dolor físico y emocional con categorías como el sexo, la criminalidad o la inteligencia, y en el recambio del siglo XIX al XX la discusión giró en torno a si el dolor era una modalidad sensorial específica o si debía ser pensado como un atributo extremo de otras sensaciones.

Rápidamente se sumaron las tecnologías y los experimentos para medir el dolor humano, y las intervenciones para evitarlo no solo involucraron autorizaciones ontológicas y morales, sino que empezaron a incluir validaciones técnicas e institucionales. ${ }^{55}$ El cuerpo de Eva no escapó a estas tecnologías y tampoco fue ajeno a múltiples elucubraciones sobre infusiones y experimentos que apuntaban a menguar sus dolores físicos insoportables. El discurso oficial trabajó desde los días previos a su muerte - y de manera más intensa el 26 y 27 de julio- con la idea de que su sacrificio personal, y el sufrimiento que conlleva, era un tributo necesario para "mitigar el dolor de los humildes". Si esta expresión había sido constituyente del discurso político de Eva y una marca discursiva original del peronismo como movimiento político, los mensajes de pésame se lo reapropiaron y habilitaron diferentes gradaciones de dolor al interior de la comunidad legítima de duelo.

En efecto, el dolor y su intensidad se asocian a la condición de clase y se asumen como más profundos entre los humildes. "Esta hora aciaga que vive la Patria, nos afecta a todos los argentinos por igual, pero, mi condición de artista modesto me asocia aún más profundamente al dolor que nos une ante la irreparable pérdida de la Sublime Abanderada del humilde" ${ }^{56}$ De manera similar se expresó Alejandro de la Rúa en su telegrama del 30 de julio. La muerte de Eva, escribió, “enluta el mundo de los humildes”. Por ello tal vez fue incluso más allá, cuando agregó que "todos los humildes del mundo rogaremos siempre por Eva Perón. Respetuosamente lo saludo".57

Es sabido que con el peronismo se implementaron reformas institucionales y políticas públicas que resultaron en una ampliación notable de la función estatal y en el reconocimiento de derechos. El discurso peronista, también se sabe, desarticula fundamentos tradicionales y abre un campo de significado para múltiples interpretaciones.

\section{Boddice 4.}

55. Noémi Tousignant, "A Quantity of Suffering: Measuring Pain as Emotion in the Mid-Twentieth-Century USA", Pain and Emotion in Modern History, ed. Rob Boddice (Londres: Palgrave Macmillan, 2014).

56. Alfredo Fidel Gallo, tarjeta de pésame escrita a mano, Buenos Aires 8 de agosto de 1952.AGNA, Buenos Aires, Archivo Intermedio, Secretaría Legal y Técnica de la Presidencia de la Nación, Fondo Fiscalía Nacional de Recuperación Patrimonial, Comisión 21, caja 2.

57. Alejandro de la Rúa, Buenos Aires, 30 de julio de 1952. AGNA, Buenos Aires, Archivo Intermedio, Secretaría Legal y Técnica de la Presidencia de la Nación, Fondo Fiscalía Nacional de Recuperación Patrimonial, Comisión 21, caja 2. 
El "dolor profundo" aparece por la articulación entre resignificación discursiva, trayectorias individuales y políticas públicas. Enrique narra el "intenso dolor que hemos experimentado por el deceso de la dignísima JEFA ESPIRITUAL DE LA NACIÓN (QEPD) gran bienhechora de todos los trabajadores y que gracias a su colosal esfuerzo en favor de la clase humilde se han logrado grandes mejoras justicialistas...eternamente agradecido...". 58

El breve mensaje de Enrique contiene palabras que nombran emociones, experiencias, juicios de valor y gratitud que son inescindibles para su vinculación subjetiva con la muerte de Eva. La "clase humilde" aparece nuevamente como un significante privilegiado para estructurar la intensidad de su dolor. La impronta del discurso oficial visible en "dignísima Jefa Espiritual” y en "bienhechora", que aparece como un recorte de la más frecuente "obra bienhechora" o "bienhechora de la humanidad", se enlaza con su agradecimiento, que se reconoce en sus propias experiencias, pasadas y durante y con el peronismo. Juana Pérez, en su telegrama, también dice que "siente mucho dolor" y, si bien su mensaje es mucho más parco que el de Enrique (no nombra ni indirectamente a Eva), coincide con él en entrelazarlo con "su obra bienhechora". 59

Las emociones no se limitan al lenguaje. Se expresan en gestos y manifestaciones corporales como las lágrimas y el temblor, o en ciertos órganos como, por ejemplo, el corazón. Este es, en la cultura occidental, el símbolo de la pureza y la fuente de donde emanan las emociones. El corazón fue el órgano que Eva entregaba como prueba de su pureza moral, de su amor y de su abnegación por los descamisados sufrientes. La frase "les vengo a dejar mi corazón" o "les dejo mi corazón” la acompañaron en la mayoría de sus intervenciones públicas. También repetía con singular monotonía que "auscultaba el corazón de los trabajadores" para "saber" lo que necesitan y "sentir" como ellos, especialmente su dolor, que el peronismo, precisamente, vino a mitigar. María Teresa asevera que "su corazón está loco de dolor" porque Eva se murió.Y Adelaida Soler escribió que le "duele el corazón”. Afirma que ese es también el "dolor de nuestro pueblo" y recurre a las espinas para transmitir la intensidad de ambos. Este dolor, insiste, "será como una espina clavada en medio del pecho, porque nuestra querida Evita se nos fue para siempre. Acepte señor la expresión de mi más sincera simpatía en su gran aflicción" ${ }^{60}$

Cuando el corazón dejaba de latir, se creía entonces, la persona estaba muerta. También el amor no correspondido "rompía” el corazón y a veces ese rechazo del

58. Enrique Garavilla por Orquesta España, Buenos Aires, 12 de agosto de 1952. AGNA, Buenos Aires, Archivo Intermedio, Secretaría Legal y Técnica de la Presidencia de la Nación, Fondo Fiscalía Nacional de Recuperación Patrimonial, Comisión 21, caja 2.

59. Juan Pérez, Buenos Aires, 1 de agosto de 1952. AGNA, Buenos Aires, Archivo Intermedio, Secretaría Legal y Técnica de la Presidencia de la Nación, Fondo Fiscalía Nacional de Recuperación Patrimonial, Comisión 21, caja 9.

60. Adelaida Soler, Buenos Aires, s.f., tarjeta de pésame escrita a mano. AGNA, Buenos Aires, Archivo Intermedio, Secretaría Legal y Técnica de la Presidencia de la Nación, Fondo Fiscalía Nacional de Recuperación Patrimonial, Comisión 21, caja 15. 
ser amado podía hacerlo "sangrar". En sintonía con el lenguaje del melodrama, Alfredo Coen afirma que su "corazón está atribulado del dolor"; la palabra "tribulación”, hoy prácticamente ausente del lenguaje cotidiano y del léxico emocional, fue usada también para expresar la intensidad y las secuelas del dolor. Alfredo asevera que tiene "el espíritu acongojado y el corazón atribulado por la irreparable pérdida sufrida por el país". Además del telegrama, escribió una carta en la que volvió a utilizar la expresión "corazón atribulado". ${ }^{61}$ En las dos ocasiones recurrió a convenciones narrativas y retóricas disponibles en su intención de transmitir la intensidad emocional y la ruptura que implicó la muerte de Eva. No era la única expresión disponible, hemos visto, pero sin duda era lo suficientemente significativa para mostrar que su corazón, y él todo, estaba roto y deshecho.

La apelación a metáforas auditivas y meteorológicas como el rayo, los truenos, la tormenta y la oscuridad, que anuncian o evocan la muerte de alguien, eran de vieja data y a mediados de siglo convivían con otras actitudes populares que son coherentes con aquellas notas o telegramas de pésame que no ahorran ni hipérboles ni excesos retóricos. En los cementerios de mediados del siglo XX, por ejemplo, se perciben manifestaciones populares en las que proliferan retratos del difunto, decoraciones abigarradas de flores y poesías escritas a mano y colocadas sobre las tumbas de una sugerente similitud en sus contenidos formales con las frases de pésame aquí analizadas y también con las poesías escritas a Eva por su muerte.

La articulación de estos mensajes, como actos expresivos y afirmativos, reposa en la "condición humilde", el "dolor profundo" y la "obra bienhechora". Esta articulación muestra no solo que el peronismo y el Estado de bienestar aparecen inextricablemente unidos y que Eva, sobre todo una vez muerta, los encarna, sino que fueron narrados como una experiencia sentida y vivida por hombres y mujeres.

\section{Consideraciones finales}

Este trabajo se apoyó en un corpus de documentos que no habían sido estudiados por los historiadores, con la intención de recuperar expresiones escritas asociadas con la muerte. Se argumenta que los mensajes de pésame son un acto performativo de ciertas normas sociales y emocionales que se expresan en convenciones narrativas y tradiciones expresivas propias de la muerte. Sin embargo, como se ha visto, no fueron todos iguales e incluso los que eran idénticos podían perseguir intenciones diferentes. El acto performativo de escribir una nota de pésame es históricamente contingente y culturalmente determinado y por ello abre la posibilidad de transformación. Hubo hombres y mujeres, que es posible imaginar como socialmente diversos, que eligieron palabras y usaron frases con la intención de ir más allá de las normas del sentir y buscaron comunicar experiencias emocionales subjetivas por

61. Alfredo Coen, Buenos Aires, 4 de agosto de 1952. AGNA, Buenos Aires, Archivo Intermedio, Secretaría Legal y Técnica de la Presidencia de la Nación, Fondo Fiscalía Nacional de Recuperación Patrimonial, Comisión 21, caja 5. La palabra tribulación también tenía una connotación religiosa que, en mi opinión, no es la que aparece en las frases breves que analizo. 
la muerte de Eva. Del abanico de palabras disponibles, aquella con el significante clave para comunicar el impacto emocional por la pérdida fue "dolor", la cual estuvo presente en el mismo momento en discursos muy diferentes. Expresiones de la cultura de masas como el tango, el bolero, el cine o el radioteatro pusieron en circulación guiones sobre el proceso de morir y el dolor por la muerte. Estos guiones, parecidos, pero no idénticos, a su vez convivieron con discusiones expertas en torno a cómo y a través de qué intervenir para medir y menguar el dolor físico, qué experiencia humana significaba dolor y si este era una modalidad sensorial específica o se trataba de un atributo extremo de otras sensaciones. La progresiva enfermedad de Eva, el deterioro de su cuerpo y de su voz, y las diversas operaciones a las que se sometió fueron acompañados con preocupación y empatía por una parte importante de la población argentina. Sin duda, quienes escribieron los documentos analizados en este artículo habían escuchado a Eva en sus recurrentes intervenciones públicas, cuando insistía que su misión dentro del peronismo era "mitigar el dolor" de los humildes. Al enunciarlo como auténtico, Eva hizo de ese dolor una cuestión de poder y, como muestran varios telegramas y tarjetas de pésame, este reconocimiento oficial, en interacción con experiencias individuales y en confrontación con discursos y acciones de los opositores políticos, permitía determinar quiénes podían hablar en nombre del dolor y tributarlo. La articulación entre el dolor en el discurso peronista, el dolor en el cuerpo de Eva y el dolor por su muerte es una clave significativa de la relación de reciprocidad que termina de consumarse en el ritual mortuorio y que tiene por testimonio los telegramas y tarjetas de pésame.

Las cartas públicas enviadas al presidente Juan Perón en ocasión del Plan Quinquenal en 1951 han sido interpretadas como una demostración de participación política en un orden crecientemente autoritario y como indicadoras del aspecto menos técnico que coexistió con la ideología de la modernización y la planificación estatal de mediados de los años 50 en occidente. ${ }^{62}$ También las cartas mandadas a Eva por mujeres generalmente solas y que permanecieron al margen del proceso de sindicalización que el peronismo alentó han permitido repensar el proceso de construcción del liderazgo carismático. ${ }^{63} \mathrm{Si}$ se considera la correspondencia de todo el periodo de gobierno, es posible advertir el carácter situado y polisémico de las identificaciones que dieron sustento al lazo con el líder. ${ }^{64}$ Los telegramas y las notas de pésame corroboran estas interpretaciones y transmiten un aspecto más íntimo y amoroso de los hombres y mujeres con la política y sus dirigentes, ${ }^{65}$ pero también muestran la evidente intersección entre Estado de

62. Elena 81. Para la participación de los trabajadores sensibles a las experiencias multisituadas que nutrieron sus reclamos de vivienda, véase Gutiérrez.

63. Guy 21.

64. Mercedes Barros y otros, "Las huellas de un sujeto en las cartas a Perón: entre las fuentes y la interpretación del primer peronismo", Revista Electrónica de Fuentes y Archivos 7.7 (2016): 234-260; Comastri, “Territorio, Estado e imaginación” 234-260.

65. Acha, "Sociedad civil"; Acha, "Cartas de amor"; Gutiérrez. 
bienestar, emociones y experiencias subjetivas. Las fluctuaciones en la intensidad de las emociones suponían una adecuación entre fidelidad política y expresiones y experiencias emocionales. La muerte de Eva reforzó su vínculo perdurable con las masas y terminó de definir un sentido de pertenencia política que es inescindible de la ideología y de ciertas emociones.

Es imposible conocer el impacto emocional de estos mensajes entre quienes los recibieron, ni siquiera se sabe si llegaron a manos del presidente. Un lápiz generalmente de color azul subrayando la palabra "pésame" o el nombre y apellido del remitente permiten imaginar que alguien, ¿la burocracia estatal peronista? ¿los integrantes de las distintas comisiones encargadas de investigar los presuntos delitos cometidos por el peronismo recientemente derrocado del gobierno?, los clasificó y ordenó. Que hayan sobrevivido a la furia antiperonista desatada con el golpe de Estado de 1955 habla del azar de la conservación, pero quizás también del significado de estos escritos incluso para aquellos que denostaban a Eva y al peronismo como fenómeno político de la Argentina contemporánea.

\section{Fuentes}

\section{Manuscritas}

Archivo General de la Nación Argentina, Buenos Aires (AGNA)

Archivo Intermedio, Secretaría Legal y Técnica de la Presidencia de la Nación, Fondo Fiscalía Nacional de Recuperación Patrimonial

\section{Impresas}

Boizard, Ricardo. Esa noche de Perón. Santiago de Chile:Teatinos, 1955.

Ghioldi, Américo. El mito de Eva Duarte. Montevideo: Compañía Impresora S.A., 1952.

\section{Periódicos y revistas}

La Gaceta (Tucumán) 1952.

Radiolandia (Buenos Aires) 1952.

\section{Bibliografía}

Aboy, Rosa. "El 'derecho a la vivienda'. Opiniones y demandas sociales en el primer peronismo”. Desarrollo Económico 44.174 (2004): 289-306. Doi: $10.2307 / 3456039$.

Acha, Omar. "Cartas de amor en la Argentina peronista: construcciones epistolares del sí mismo, del sentimiento y del lazo político populista”. Nuevo Mundo Mundos Nuevos (2007): 1-14. Doi: 10.4000/nuevomundo.12272. 
. "Sociedad civil y sociedad política durante el primer peronismo". Desarrollo Económico 44.174 (2004): 199-230.

Barros, Mercedes y otros. "Las huellas de un sujeto en las cartas a Perón: entre las fuentes y la interpretación del Primer Peronismo”. Revista Electrónica de Fuentes y Archivos 7.7 (2016): 234-60.

Bjerg, María. “Una genealogía de la historia de las emociones”. Quinto Sol 23.1 (2019): 1-20. Doi: 10.19137/qs.v23i1.2372.

Boddice, Rob. The History of Emotions. Manchester: Manchester University Press, 2018.

Bourke, Joanna. The Story of Pain. From Prayer to Painkillers. Nueva York / Oxford: Oxford University Press, 2014.

Brennan, Michael. "Condolence Books: Language and Meaning in the Mourning for Hillsborough and Diana”. Death Studies 32.4 (2008): 326-351.

Caimari, Lila. "Derrotar la distancia. Articulación al mundo y políticas de la conexión en la Argentina, 1870-1910”. Estudios Sociales del Estado 5.10 (2019): 128-167.

Collado,Adriana. “Arquitectura moderna para el servicio postal - Argentina, 19471955”. Arquitectura moderna y estado en Argentina: edificios para correos y telecomunicaciones (1947-1955). Ed. Adriana Collado. Buenos Aires: Centro de Documentación de Arte y Arquitectura Latinoamericana / Facultad de Arquitectura, Diseño y Urbanismo de la Universidad Nacional del Litoral, 2013.

Comastri, Hernán. "Productividad y política obrera desde las bases: la imaginación técnica popular en las cartas a Perón (1946-1955)”. Quinto Sol 24.1 (2020): 1-18. Doi: 10.19137/qs.v24i1.3571.

. "Territorio, Estado e imaginación técnica popular durante el primer peronismo: políticas públicas, prensa y cartas a Perón (1946-1955)”. Estudios Sociales del Estado 4.8 (2018): 124-150. Doi: 10.35305/ese.v4i8.130.

Elena, Eduardo. "What the People Want: State Planning and Political Participation in Peronist Argentina, 1946-1955". Journal of Latin American Studies 37.1 (2005): 81-108.

Fraser, Nicholas y Marysa Navarro. Evita: The Real Life of Eva Perón. Nueva York: W.W. Norton \& Company, 1996.

Gayol, Sandra. "La otra cara de la felicidad: dolor y martirio en el peronismo clásico”. Anuario del Instituto de Historia Argentina 20.1 (2020): e110. Doi: 10.24215/2314257Xe110.

González, Arish Tatiana. "Economic Disparity Yet Resulting Similarity: The 'Double Paradox' of Argentina's and Mexico's Electric Telegraph and Telephone Difusion, 1851-1997". Tesis de doctorado en Filosofia, London School of Economics and Political Science, 2010.

Gould, Deborah. "On Affect and Protest". Political Emotions. New Agendas in Communication. Eds. Janet Staiger y otros. Nueva York: Routledge, 2010.

Gutiérrez, Florencia. "Vivir en un pueblo azucarero: entre el asistencialismo empresarial y el derecho al bienestar. Tucumán durante el primer peronismo”. 
Comunidades, historia local e historia de pueblos. Huellas de su formación. Ed. Mirta Zaida Lobato. Buenos Aires: Prometeo Libros, 2020.

Guy, Donna J. Creating Charismatic Bonds in Argentina: Letters to Juan and Eva Perón. Albuquerque: University of New Mexico Press, 2016.

Healey, Mark. El Peronismo entre las ruinas: el terremoto y la reconstrucción de San Juan. Buenos Aires: Siglo XXI Editores, 2012.

Hochschild, Arlie Russell. "Emotion Work, Feeling Rules, and Social Structure". American Journal of Sociology 85.3 (1979): 551-575.

Kohan, Martín. Ojos brujos: fábulas de amor en la cultura de masas. Buenos Aires: Ediciones Godot, 2018.

Kriger, Clara. Cine y peronismo: el estado en escena. Buenos Aires: Siglo XXI Editores, 2009.

Leonardi,Yanina Andrea."Teatro y políticas públicas durante el primer peronismo”. Peronismo y representación: escritura, imágenes y políticas del pueblo. Comp. Carina González. Buenos Aires: Final Abierto, 2015.

Martin, J. R. y David Rose. Working with discourse: meaning beyond the clause. Londres / Nueva York: Continuum, 2003.

Mauss, Marcel. 'L' expression obligatoire des sentiments (rituels oraux funéraires australiens)". Journal de Psychologie 18 (1921): 1-8.

McElroy, Kathleen. "You Must Remember This: Obituaries and the Civil Rights Movement". Journal of Black Studies 44.4 (2013): 335-355.

Moscoso Sarabia, Javier. "De la Historia de las Emociones a la Historia de la Experiencia. Los dibujos y notas de un marino español durante la Guerra Civil”. La cultura de las emociones y las emociones en la cultura española contemporánea (siglos XVIII-XXI). Eds. Luisa Elena Delgado y otros. Madrid: Cátedra, 2018.

Nussbaum, Martha C. Las emociones políticas. ¿Por qué el amor es importante para la justicia? Barcelona: Paidós, 2014.

Ortiz Bergia, María José. "Cartas públicas: claves metodológicas y usos históricos posibles". Prohistoria 22.31 (2019): 161-180.

Petrucci, Armando. Writing the Dead. Death and Writing Strategies in the Western Tradition. Stanford: Stanford University Press, 1998.

Rosenwein, Barbara H. "Problems and Methods in the History of Emotions". Passions in Context I 1 (2010): 1-32.

Scheer, Monique. "Are Emotions a Kind of Practice (and Is That What Makes Them Have a History)? A Bourdieuian Approach to Understanding Emotion". History and Theory 51.2 (2012): 193-220.

Tousignant, Noémi. "A Quantity of Suffering: Measuring Pain as Emotion in the Mid-Twentieth-Century USA". Pain and Emotion in Modern History. Ed. Rob Boddice. Londres: Palgrave Macmillan, 2014.

Ulanovsky, Carlos. Días de radio: historia de la radio en Argentina. Buenos Aires: Espasa Calpe, 1995. 